\title{
Arayüz Tasarımları İçin Prototip Kullanımı
}

Arş. Gör. Samed Sakman

\section{Özet}

Son yirmi yıl içerisinde internetin giderek yaygınlaşması, insanların elektronik olarak iletişim kurdukları farklı cihaz ve platformların ortaya çıkmasını sağlamıștır. Yaşam biçimini tamamen değiştiren bu yeni iletişim kanallarının herkes tarafindan kullanılabilmesini sağlayan, cihaz ve kullanııı araşında bir yeni iletişim kanallarının herkes tarafindan kullanılabilmesini sağlayan, cihaz ve kullanıcı arasında bir
etkileșim köprüsü görevi gören arayüz tasarımlarıdır. Arayüz üretiminden önce; tasarımların akışını, düzgün ve tutarlı olup olmadığıı test edebilmek için prototip tekniklerinden yararlanılmaktadır. Prototip olușturmak kullanıcı deneyimini artırmak açısından önemlidir. Arayüz tasarımlarında prototip teknikleri, gerçekçi kullanıcı deneyimi sağlayan bilgisayar tabanlı uygulamalar olan yüksek etkileşimli (high-fidelity) ve genellikle kullanıcı deneyimi sunmayan, kağıt bazlı uygulamalar olan düsü̈k etkileșimli (low-fidelity) olmak üzere ikiye ayrılmaktadır. Bu araştırma ile, tasarımcıların prototip etkileşimli (low-fidelity) olmak üzere ikiye ayrılmaktadır. Bu araştırma ile, tasarımcıların prototip
tekniklerinden faydalanarak; anlaşılır, işlevsel ve tutarlı arayüzlerin geliştirilmesine katkı sağlamak hedeflenmektedir.

Anahtar Kelimeler: Prototip Tasarımı, Arayüz Tasarımı, Prototip Teknikleri, Etkileșim Tasarımı

\section{PROTOTYPE USAGE FOR INTERFACE DESIGNS}

\section{Abstract}

In the last twenty years with the growing popularity of the internet has led people to develop different devices and platforms which they communicate electronically. The interface designs are acting as the bridge as an interaction between the device and user which enables the use of these new cummunication channels by everyone that competely change the way of life. Before production cummunication channels by everyone that competely change the way of life. Before production and consistency. Building a prototype is important to improve the user experience. There are two types of prototype design. One of them is high-fidelty prototypes which is a computer-based design and provides a realistic user experience. The other is low-fidelity prototypes which is paper-based applications. With this research, it is aimed to contribute designers to develop understandable, functional and consistent interfaces by using the prototype techniques.

Keywords: Prototype Design, Interface Design, Prototype Techniques, Interaction Design

Arş. Gör. Samed Sakman, Kırrkkale Üniversitesi, Güzel Sanatlar Fakültesi, Resim Bölümü , Krrıkale. E-posta: samedsakman@kku.edu.tr 


\section{Giriş}

Çağımıza yön veren en etkili makine şüphesiz ki bilgisayarlardır. Her geçen gün gelişen teknolojisi; sosyal yaşamda, bilimde, eğitimde ve dahi sanatta yeni gelişmelere yol açarak hayatı kolaylaştırmaya ve değiştirmeye devam etmektedir. Modern dünyanın neredeyse her ferdi, bilgisayarla bir şekilde etkileşim içerisindedir. Bununla birlikte bilgisayarların insanlığa yararlı bir araç olabileceğini öngören ilk kişi muhtemelen Amerikalı bilim adamı ve mühendis Vannevar Bush'tur. Bush'un, "As We May Think" (1945) adlı makalesinde bahsettiği Memex (memory-index) adlı yapı, bilgisayarların gelecekteki bilgi depolama, depolanan bilgiye ulaşma işlevlerini ve multimedya doğasını öngörerek çarpıcı bir ileri görüşlülük örneği sunmaktadır.

Bush'un ilham veren fikirlerinden sonra gerek askeri alanda gerekse özel kullanım için çeşitli bilgisayarlar tasarlanmış ve kullanılmış olsa da, Apple firmasının 1984 yılında tasarlayıp piyasaya sürdüğü Macintosh adlı bilgisayar grafiksel arayüz kullanan ve ticari başarıya ulaşmış ilk ürün olma niteliğini taşımaktadır (Görsel 1). ${ }^{1}$ Bu ürünle birlikte ilk defa dosyaların kağıt, dizinlerin de klasör gibi göründüğü bir masaüstü metaforu kullanılmıştır. Kullanıcının masaüstünün her yerine istediği gibi tassıyıp bırakabileceği bir küme masaüstü nesnesinin, örneğin hesap makinesi, not defteri ve çalar saatin yanı sıra dosyalarını üzerine sürükleyip silebileceği bir de çöp kutusu bulunmaktadır. Açılır menüler de ilk kez sunulmaktadır (Batı, 2012: 33).

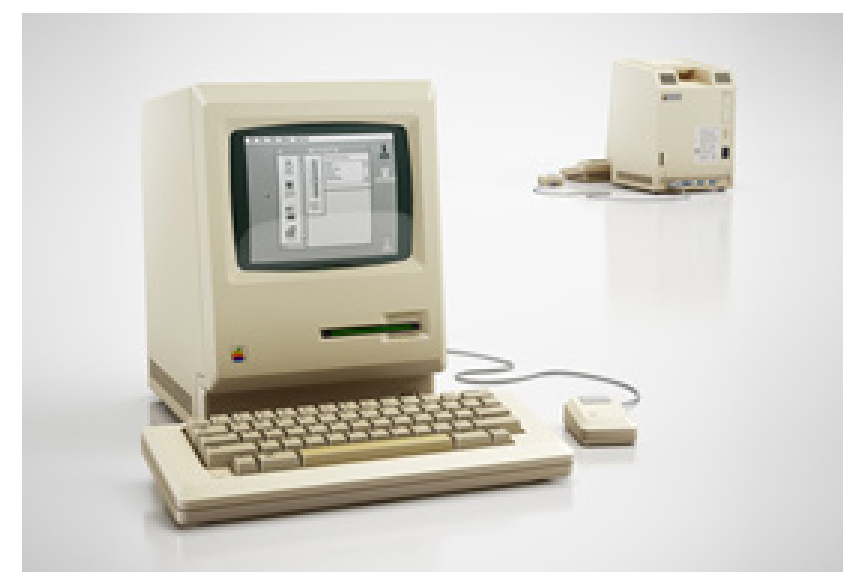

Görsel I. 1984 Yılında Piyasaya Sürülen Apple Macintosh
Microsoft firmasının ürettiği ve ilk olarak 1985 yılında satışa sunulan Windows işletim sistemi, 1995 yılında piyasaya sürülen Windows 95 (Görsel 2) versiyonu ile tüm zamanların en çok satan grafiksel kullanıc arayüzü olmuştur. ${ }^{2}$ Bu süreç içerisinde Microsoft ve Apple firmalarının işletim sistemi ve grafiksel kullanıcı arayüzlerindeki başarısı geliştirdikler yeni versiyonlarla devam etmiştir. Internetin yaygınlaşması ile birlikte, insan-makina etkileşimi daha küçük boyutlu cihazlara taşınarak etkinliğini sürdürmüştür. Grafiksel kullanıcı arayüzlerinin önemi ve gerekliliği de bu gelişmelerle doğru orantılı bir biçimde değer kazanmıştır.

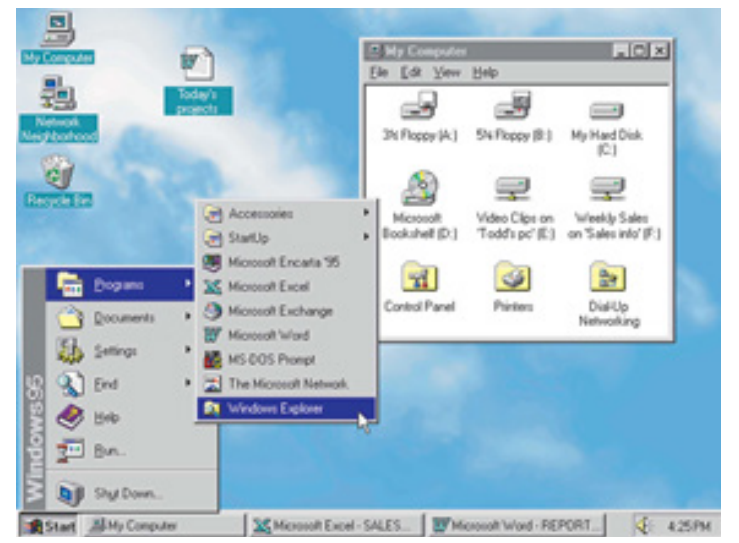

Görsel 2. Microsoft Windows 95 Grafiksel Kullanıcı Arayüzü

\section{Kullanıcı Arayüzleri ve Tasarımı}

Grafiksel kullanıcı arayüzü, makineleri kontrol edebilmek için işletim sistemini (OS) oluşturan komutları ve bu komutların çıtılırını ezberlemek yerine; fare, klavye, monitör ve kumanda gibi donanımsal araçlar yardımıyla etkileşimde bulunulan simgeler, pencereler, düğmeler, hipermetinler (hypertext) ve panellerin tümünü ifade etmek için kullanılan genel addır. Günümüze kadar bilgisayar ve grafiksel kullanıcı arayüzü üreten firmaların her biri, birbirinden farklı özellikler ve yenilikler taşıyarak yine birbirlerini etkilemişlerdir.

Son yirmi yıl içerisinde internetin giderek yaygınlaşması, insanların elektronik olarak iletişim kurdukları farklı cihazlar ve farklı platformların ortaya çıkmasını sağlamıştır. Bu durum, arayüz tasarımlarının da çeşitlenip ge-

' http://arstechnica.com/features/2005/05/guil7/ 
lişmesine yol açmıştır. 2007 yılında Apple firması tarafından satışa sunulan iPhone ve daha sonra 2010 yılında piyasaya sürülen iPad ile birlikte hayatımıza giren akıllı taşınabilir cihazlar, internet ve bilgisayar kullanım alışkanlıklarımızda köklü değişimlere yol açmışıı. Hem kişisel hem de iş hayatında kullanılan bu cihazlar; ergonomik yapıları, kolay kullanım sağlayan arayüzleri ve daha uzun pil ömürleriyle bilgisayarların yerini almışır. Insanların kolayca yanlarında taşıyabildiği ve gittikleri her yerde internete erişebildikleri bu cihazlar sayesinde internet sayfaları da evrilmiştir. Bu durum; sosyal, siyasal ve ekonomik olarak toplumları etkileyebilen "sosyal medya" kavramının doğmasını sağlamıştır.

Mobil cihazların kullanıcı arayüzleri, üreticisine göre değiştiği söylenebilir. Apple, dünyanın ilk akıllı cihazı olma özelliğine sahip iPhone için tasarladığı mobil işletim sistemi ve arayüzünü iPad tabletlerinde de kullanmıştır. Samsung, Sony, LG, HTC vb. gibi pazarın diğer figürleri açık kaynak kodlu Android işletim sistemi ve arayüzünü kullanmaktadır. Bu arayüzün genel bir çizgisi olmakla birlikte, üreticiye göre ufak tefek değişikliklerle müşteriye sunulmaktadır. Daha ekonomik ürünlere sahip olması sebebiyle Android, dünyanın en çok kullanılan arayüzü olmaya devam etmektedir. ${ }^{3}$

Insanların yaşam biçimini tamamen değiştiren mobil cihaz ve sanal platformların herkes tarafından kullanılabilmesini sağlayan, cihaz ve kullanıcı arasında bir iletişim ve etkileşim köprüsü görevi gören arayüz tasarımlarıdır. Bu arayüzlerin en önemli amacı makinenin etkin işleyişini ve kontrolünü sağlamaktır. Bu amaç doğrultusunda kullanılan arayüzün; kendiliğinden anlaşılabilir, etkili ve kullanıcı dostu olması gerekmektedir. Arayüz tasarımlarının amacına ulaşarak başarılı olabilmesi için; kullanııının amaçları, alışkanlıkları ve kullanım deneyimi göz önünde bulundurulmalıdır.

Arayüzlerin tasarlanması sürecinde bir takım tasarım ve estetik ilkelerden yararlanmak, yalnızca materyali düzenlemek yerine yaratıcılığa katkı sağlayarak kullanıcı deneyimi ve sadakati en üst seviyeye ulaştıracaktır. Blair ve Zender (2008), birlikte kaleme aldıkları "Etkileşim Tasarımında Kullanıcı Arayüzü Tasarım Prensipleri" adlı makalelerinde şunu ifade etmektedirler:

Edward Tufte'ın "The Visual Display of Quantitative Information and Visual Explanations" kitabındaki mükemmel örnekler gibi tasarım ilkeleri, açık kurallar oluşturarak yeni özellikler tanımlar. Burada önerilen ilkeler, bir arayüzü tanımlayan parametrelerle entegre olmak durumundadır. Parametreler ve ilkeler birlikte çalışıı̆ında, tasarımcıya yenilik, güç ve yaratıcılık katacağına inanmaktayız. Eğer ilkeler uygun ve düzenli olarak uygulanırsa, sadece günümüze değil geleceğin yenilikçi ve daha gelişmiş arayüzlerinin tasarlanmasına ışık tutacaktır.

Uygulama tasarımı ve yazııı mühendisliği alanlarında yaptıkları çalışmalarla tanınan Larry Constantine ve Lucy Lockwood (1999), kullanıcı merkezli tasarım kavramını açıklarken, arayüz tasarımının olmazsa olmaz ana prensiplerini aşağıdaki şekilde tanımlamaktadırlar:

Yapı Prensibi: Yapı prensibi genel kullanıı arayüzü mimarisi ile ilgilidir. Tasarım, anlamlı ve yararlı bir şekilde kullanıcı arayüzünü kasıtı olarak organize etmelidir. Belirgin ve kullanıcılara tanınabilir tutarlı modeller içermelidir. İlgili içerikler bir arada kullanılırken, alakasız olanlar birbirinden ayrımalıdır.

Sadelik Prensibi: Tasarım sade olmalıdır. Iletişim kullanıcının kendi dilinde ve anlaşılabilir olmalıdır. Daha uzun işlemler için anlamlı ve ilişkili kısayollar temin edilmelidir.

Görünürlük Prensibi: Tasarımda; gereksiz ve yabancı bilgilerle kullanıcıyı rahatsız etmeden, gerekli tüm seçenek ve materyali görünür kılmak gerekir. İyi bir tasarım, gereksiz bilgiler veya alternatif yollarla kullanıcıyı korkutmamalıdır.

Geri Bildirim Prensibi: Tasarım, durum ve koşul değişikliklerinde veya kullanıcılarla alakalı hatalar ve istisnalar durumunda, eylem veya yorumlarla kullanıcıyı haberdar etmelidir.

Hesaplanabilirlik Prensibi: Tasarım esnek ve hesaplanabilir olmalıdır. Ayrıca mümkün olduğunca tüm varyasyonları hesaplayıp, makul eylemleri yorumlayarak hataları en aza indirgemek gerekir.

Yeniden Kullanılabilirlik Prensibi: Tasarım, iç ve dış bileşenleri ve davranışları yeniden kullanabilmelidir. Amaca tutarılık sağlanmalıdır. Bu durum kullanıcıların yeniden düşünme veya hatırlama intiyacını azaltır.

Internete bağlanabilen cihazların çeşitliliğinin artmasıyla birlikte internet siteleri ve mobil uygulamaları arayüz tasarımlarının esnek ve uyarlanabilir olması gerekmektedir. Arayüz tasarımlarının; bilgisayarlar, tabletler ve akıllı telefonlar gibi farklı farklı ekran çözünürlüklerine sahip tüm platformlarda sorunsuz ve tutarlı bir şekilde çalışması, insan ve makine arasındaki etkileşimi en üst seviyeye taşımaktadır. Bu bağlamda, arayüz üretiminden önce tasarımların akışı, düzgün ve tutarlı olup olmadığını test edebilmek ve ilerde karşılaşılabilecek sorun ve aksaklıkların önceden deneyimlenmesi için prototip uygulamalarından yararlanılmaktadır. 


\section{Prototip Teknikleri}

Prototipin sözlük anlamı, "ilk örnek, model"dir. Prototip oluşturmak kullanıcı deneyimini artırmak açısından önemlidir. Son ürünün gerçekçi bir simülasyonu olan prototip; fikirleri keşfetmek, bir özellik geliştirmek veya geri bildirim almak için genel tasarım konseptini görmemizi sağlayan gerçekçi bir taslaktır. "İnternet siteleri ve uygulama arayüzlerinde tasarımcı, müşteri ve kullanıc perspektifinden; içerik, estetik ve etkileşim seviyesini belirlemek için kullanılmaktadırlar" (Walker, Takayama ve Landey, 2002: 661).

Arayüz tasarımları için prototip teknikleri, yüksek etkileşimli (high-fidelity) ve düşük etkileşimli (low-fidelity) olmak üzere ikiye ayrılmaktadır (Rogers, Preece ve Sharp, 2002). Yüksek etkileşimli prototipler gerçekçi kullanıcı deneyimi sağlayan bilgisayar tabanlı tasarımlardır. Tasarım ve uygulama olarak, son ürüne oldukça yakın olduğundan, kullanıcı deneyimi verilerinin ve geri bildirimlerin toplanmasını kolaylaştırmaktadır. Düşük etkileşimli prototipler ise genellikle kağıt bazlı uygulamalardır. Basit el çizimlerinden ve karalamalardan oluşmaktadır. Uygulaması basit ve hızlı olduğundan, alternatif tasarım çözümleri sağlamada yardımcı olabilmektedir.

Tasarım fikri temsillerinin geliştirilmesi, tasarımcıların önem verdiği konuların başında gelmektedir. Hayali bir fikri, kullanıııya açıklamanın yolu onu kelimelere dökmek veya görsel bir sunum hazırlamaktan yani prototip oluşturmaktan geçmektedir. Fikirlerin anlaşılabilmesi ve değer kazanması bakımından prototip oluşturmak daima tatmin edici olmaktadır. Etkileşim tasarımında çeşitli prototip oluşturma teknikleri mevcuttur. Senaryo oluşturma, taslak çizim ve bilgisayar tabanlı dinamik prototipler en çok tercih edilenler arasındadır.

Senaryo oluşturmak, bir tasarım fikrini kelimelerle anlatmaktır. Arayüz tasarımının tüm işlev ve işleyişlerini, aşama sırasını, görsel özelliklerini ve etkileşim yeteneklerini bir form aracılığılla yazıya dökerek kullanıının zihninde canlandırmayı amaçlamaktadır. Buna rağmen, ne kadar iyi ve özgün kaleme alınırsa alınsın, etkinlik anlamında soyut bir anlatımdan öteye geçememektedir. Tasarımcının hayal dünyası ile kullanıcının hayal dünyası farklı olacağından yanlış anlamalar ve beklentiler doğabilmektedir. Arayüz tasarım fikrinin, kullanıcı tarafından deneyimlenemediği bu teknik ile kullanıcı geri dönüşü alınamayacağından tasarımın tamamlanma süresi uzayabilmektedir. Bu durum, tasarımcıda ve kullanıcıda istek kaybına ve derişim eksikliklerine sebebiyet verebilmektedir. Senaryo oluşturma tekniği düşük etkileşimli prototip sınıfına girmektedir.
Taslak çizim tekniği, kelimelerle birlikte görsel unsurlar da barındırmaktadır. Arayüz tasarım fikrinin genel çerçevesi, kağıt ve kalem yardımıyla elle çizilerek, kullanıııda bir izlenim uyandırmak amaçlanmaktadır (Görsel 2). Etkileşimin her aşaması basitçe çizilerek, nesnelerin konumu ve çalışma mantığı kullanıcıya aktarılmaya çalışılmaktadır. Senaryo oluşturma tekniğine göre daha somut ve anlaşlır olan taslak çizimler, hızlı uygulanabilmeleri bakımından da tasarımcılar tarafından çokça tercih edilmektedir. Buna rağmen tıpkı senaryo oluşturma tekniği gibi, taslak çizimlerde tam anlamıyla gerçekçi bir kullanıcı deneyimi sunamamaktadır. Bu bakımdan düşük etkileşimli prototip sınıfına girmektedir.

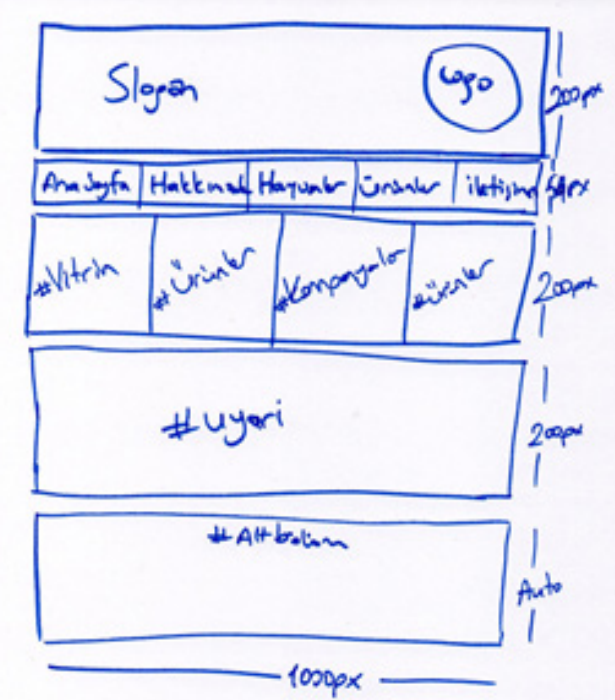

Görsel 3. Taslak Çizim Tekniği ile Hazırlanmış Bir Web Sayfası Prototipi.

Bilgisayar tabanlı dinamik prototipler, görünüş ve işleyiş bakımından gerçekçi bir kullanıı deneyimi sunmaktadır. Son ürüne oldukça benzeyen dinamik prototipler, çeşitli bilgisayar uygulamaları aracılığıyla hızı bir şekilde tasarlanabilmektedir. Yüksek etkileşimli sınıfa giren dinamik prototipler, arayüz tasarımının içerebileceği tüm teknik uygulamaları erkenden deneyimleme imkânı sağladığından; problemleri öngörme, hızlı manevra kabiliyeti ve de gerçekçi sergileme fırsatları sunmaktadır. Bilgisayar programları aracılığılla hızlı taslaklar (wireframes), gerçek zamanlı etkileşim uygulamaları (butonlar, bağlantılar, animasyonlar, sesler vb.), gerçekçi kullanıcı senaryoları ve akış şemaları oluşturulabilmektedir. 


\section{Bilgisayar Tabanlı Prototip Tasarımı}

Bilgisayar tabanlı prototipler tasarlayabilmekiçin kullanılan birçok uygulama (application) bulunmaktadır. Sketch, Macaw, Avocode ve Webflow bu uygulamalardan bazılarıdır fakat Adobe'un geliştirdiği ve piyasaya sürdüğü "XD" (Experience Design), işlevsellik ve kullanılabilirlik bakımından diğer uygulamalardan ayrılmaktadır. Bu uygulama sayesinde; hem arayüz tasarımları geliştirilebilmekte, hem de gerçekçi bir prototip simülasyonu eklentisi sayesinde geliştirilen arayüzler hiçbir yazılım bilgisine ihtiyaç duyulmadan son ürüne oldukça benzer bir biçimde test edilebilmektedir.

XD'nin açılış ekranında (Görsel 4) öncelikle çalışmanın ölçülerini seçmemiz istenmektedir. iPhone, iPad, android telefonlar ve tabletlerin çeşitli versiyonlarının ölçüleri seçim ekranında hazır olarak karşımıza gelmektedir. Aynı zamanda web arayüzü tasarlamak için de hazır ölçü kalıpları bulunmaktadır. Ayrıca tüm bu kalıpların dışında çalışma sayfası istenilen ebatlarda da belirlenebilmektedir. Açılıs ekranında ücretsiz bir șekilde Apple iOS, Google ve Microsoft Windows için arayüz tasarım materyalleri (UI Kits) de indirilebilmektedir.

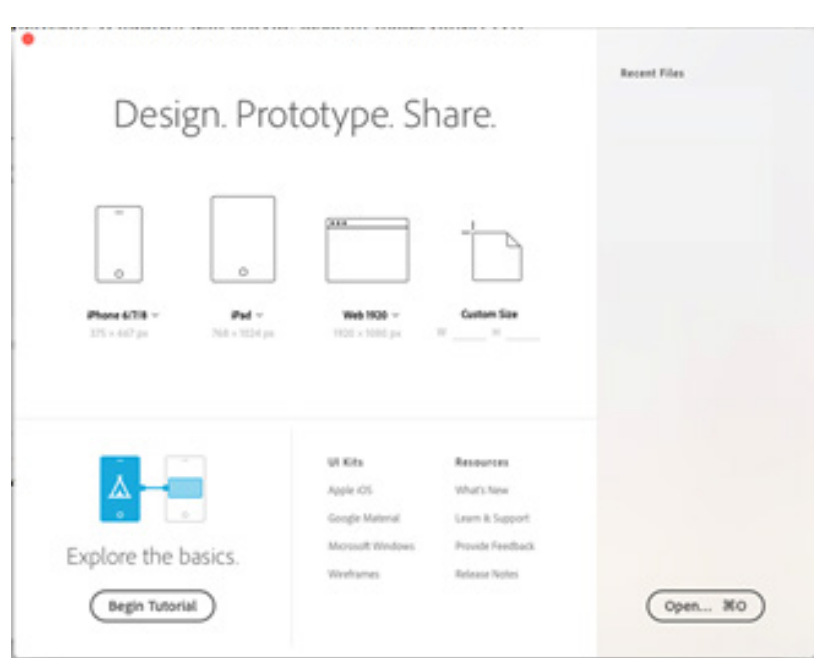

XD Uygulamasıının Açוlış Ekranı.

Uygulamanın kendi arayüzü oldukça sade ve anlaşılır bir biçimde karşımıza çıkmaktadır. Çizim ve tasarım araçları yetersiz gibi görünse de bir arayüz tasarımı geliştirmek için ihtiyaç duyulan metin, dikdörtgen, elips ve kalemle çizim araçları gibi tüm detaylar uygulamada yer almaktadır. Ayrıca Photoshop, Illustrator ve Sketch gibi diğer tasarım uygulamaların- dan kopyala-yapıştır veya sürükle-bırak ile pixel veya vektörel tabanlı tüm tasarım öğeleri aktarılabilmektedir. Geliştirilecek arayüzün tüm katmanları çalışma yüzeyleri (artboards) kullanılarak tek bir ekranda oluşturulabilmektedir (Görsel 5). Tasarım materyalleri konumlandırılırken, hizalama ızgaralarına otomatik olarak hizalanmakta ve çalışma yüzeyi içerisinde boşta kalan alanların ebatları ekranda dinamik biçimde yazmaktadır. Uygulama bu yönüyle tasarımcıya büyük kolaylıklar sağlamaktadır.

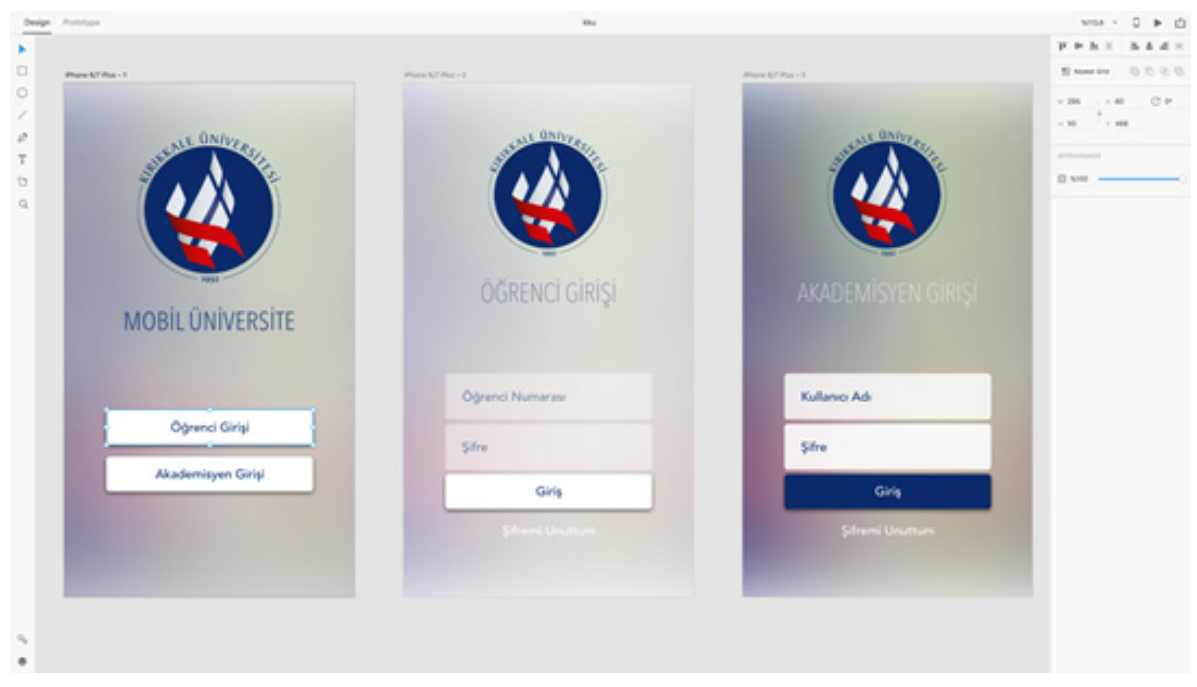

Görsel 5. Çalsşma Yüzeyleri Görünümü

Tasarlanan arayüzün prototipini oluşturmak için, uygulamanın sol üst kısmında yer alan "Prototype" sekmesine geçilmektedir. Bu kısımda oluşturulan çalışma yüzeylerinde bulunan içeriklerin simülasyonu kurgulanmaktadır. Görsel 5'de ilk çalışma yüzeyinde yer alan "Öğrenci Girişi" adlı butona tıklayıp ikinci çalışma yüzeyine sürükleyerek, "Öğrenci Girişi" sayfasına yönlendirme simülasyonu gerçekleştirilmiştir. Aynı işlem ilk çalışma yüzeyinde yer alan "Akademisyen Girişi" butonu için de yapılmıştır (Görsel 6). 


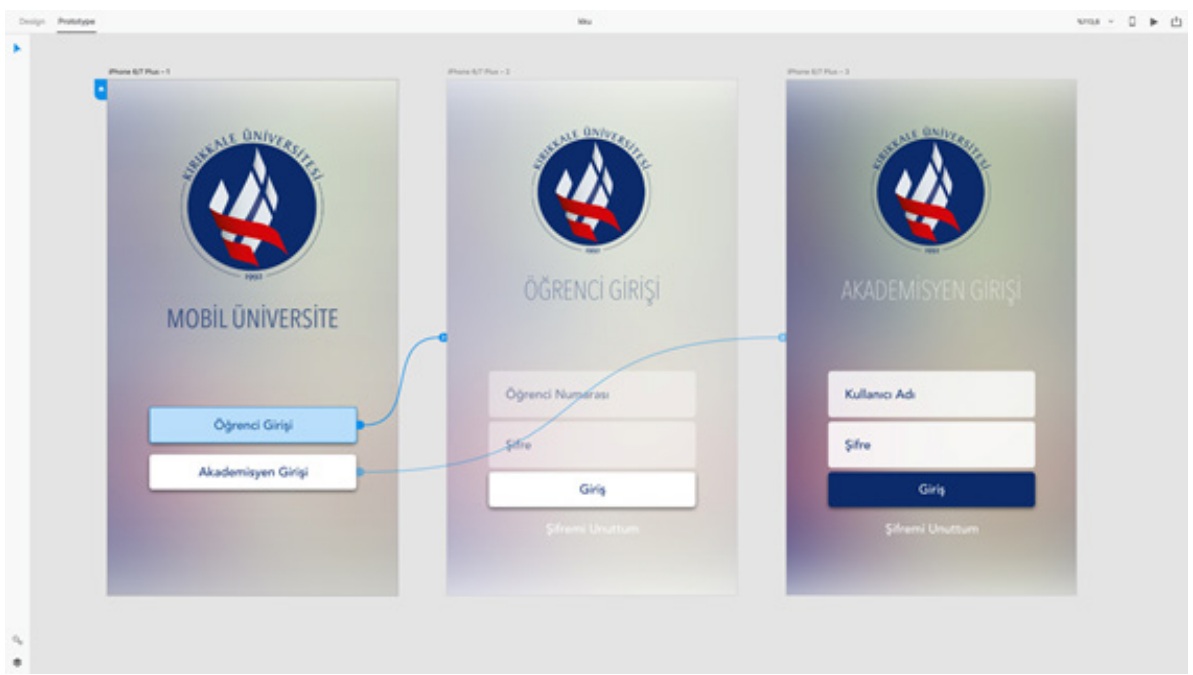

Görsel 6. Hazırlanan Tasarımın Dinamik Prototipinin Oluşturulması

Ekranın sağ üst köşesinde yer alan ön izleme modlarından; “Device Preview " ile oluşturulan prototip direkt olarak bir mobil cihazda çalıştırılarak ön izlemesi sağlanabilmektedir. Bir diğer ön izleme modu olan "Desktop Preview " ile de, oluşturulan prototipin simülasyonunun uygulama üzerinden ön izlemesi gerçekleştirilerek video kaydı da alınabilmektedir. (Görsel 7). Böylece hiçbir kodlama bilgisine ihtiyaç duymadan arayüzün tüm özellikleri çalıştırılmakta ve test edilebilmektedir.

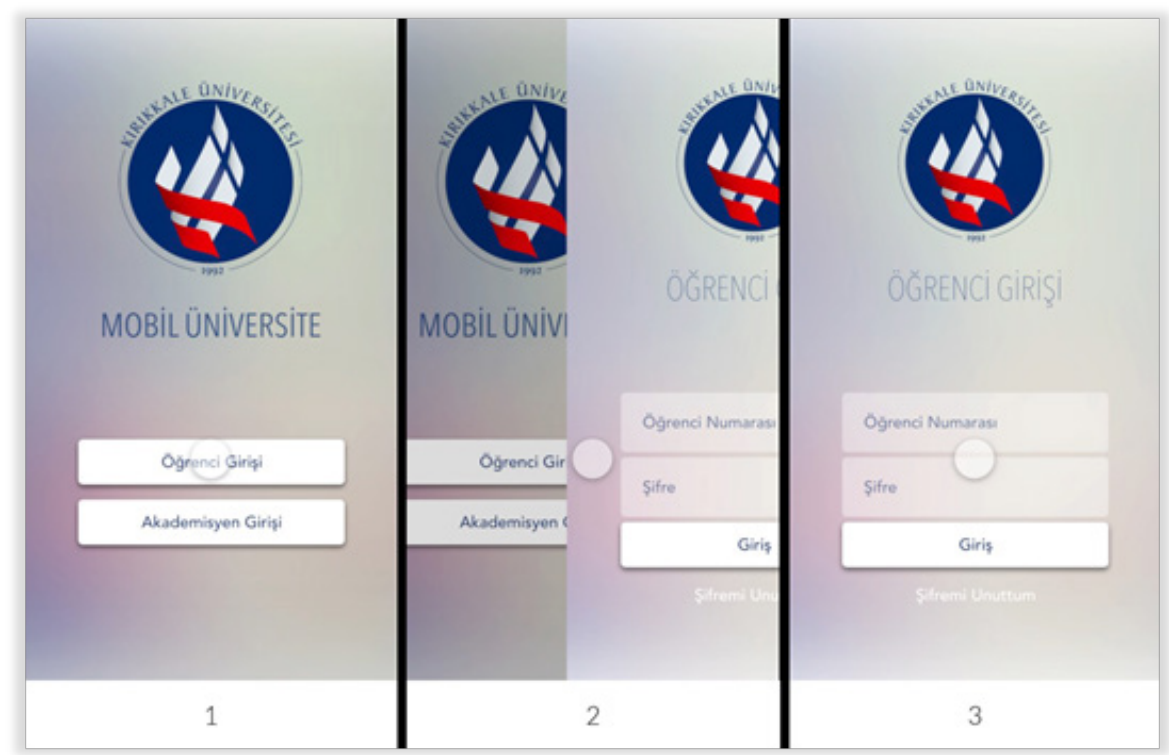

Görsel 7. Prototip Ön İzleme Modu ile Arayüzün Gerçekçi Simülasyonu.

\section{Prototip Teknikleri}

Teknolojinin büyük bir hızla gelişmesi ile birlikte yeni elektronik cihazlar da hayatımıza girmeye devam etmektedir. Illk bilgisayardan günümüzün akıllı elektronik aletlerine kadar, insanla makinenin etkileşimi kullanıcı arayüzleriyle birlikte gerçekleşmiştir. Cihazlar ve internet platformları gelecekte ne kadar gelişirse gelişsin, değişmeyecek tek şey kullanıc arayüzlerinin gerekliliğidir. Makinelerin ve web sayfalarının etkin ve hızlı kullanılabilmesi için arayüzlerin profesyoneller tarafından tasarlanması bir mecburiyettir. İkili üretim mantığından hareketle işlevsellik ve tasarım birliği sağlanmalıdır.

Kullanıcıyı yormayan, basit, anlamlı ve tutarlı arayüzler bir takım deneyim ve testler ışığında ortaya çıkmaktadır. Ürünün prototipi oluşturularak, son halinden önce uygulamalar yardımıyla gerçekçi bir simülasyona dönüştürülmesi, olası hataların ve yapısal bozuklukların önüne geçerek zamanveparakaybınıönleyebilmektedir. Bubağlamdaarayüztasarımlarında prototip uygulamaları oldukça önem kazanmaktadır.

Tasarımcılar, arayüz tasarım fikirlerini doğru bir biçimde aktarabilmek için, kullanıcıya tam bir etkileşim deneyimi yaşatmak durumundadır. Gelişen teknolojik altyapıya rağmen kağıt ve kalemle geleneksel sunum tekniklerini tercih etmek güven ve zaman kaybına neden olabilmektedir. Tasarlanan arayüzün çeşitli cihazlardaki görünümünü ve davranışını kullanıcının deneyimlemesini sağlamak, şüphesiz ki tasarımcıya artı değer kazandırmaktadır. Bu bağlamda dinamik prototipler oluşturmaya yarayan bilgisayar uygulamalarını kullanabilmek oldukça önemlidir.

Günümüzde mevcut prototip tasarım uygulamaları, tasarımcıların işin oldukça kolaylaștırmaktadır. Bu uygulamalar sayesinde; tasarımda kullanılan obje ve nesneler, sürükle bırak teknolojisiyle istenilen çalışma yüzeyine bağlanarak, hiçbir komut satırına gerek duyulmaksızın dinamik içerikler oluşturulabilmektedir. Tasarlanan bir arayüz, akıllı telefon, tablet veya web ortamında gerçek zamanlı olarak simüle edilebilmekte ve gerçekçi bir kullanıcı deneyimi sağlanmaktadır. 


\section{Kaynakça}

Batı, A. (2012) Insan-Bilgisayar Etkileşiminde Arayüz Tasarımı ve Metaforlar, Sanatta Yeterlik Tezi, Marmara Üniversitesi Güzel Sanatlar Enstitüsü, İstanbul.

Blair-Early, A. ve Zender, M. (2008). “User Interface Design Principles for Interaction Design”, Design Issues, 24 (3), 85-107.

Bush, V. (1945). "As We May Think". The Atlantic Monthly, July, I I 2-I 24.

Constantine, L. ve Lockwood, L. (1999). Software for Use: A Practical Guide to the Essential Models and Methods of Usage-Centered Design, Reading, MA: Addison-Wesley.

Rogers, J., Preece, Y., Sharp, H. (2002). Interaction Design: Beyond Human-Computer Interaction. New York: John Wiley.

Walker, M., Takayama, L. ve Landay, J.A. (2002). "High-FIdelity or Low-Fidelity, Paper or Computer? Choosing Attributes When Testing Web Prototypes", Proceedings of the Human Factor and Ergonomics Society 46th Annual Meeting.

\section{Internet Kaynakları}

Internet: History of the graphical user interface (200I, Nov). Wikipedia.

Web: https://en.wikipedia.org/wiki/History of the graphical user interface adresinden 3 Mayıs 2017 tarihinde alınmıştır.

Internet: A History of the GUI (2005, May). Ars Technica.

Web: http://arstechnica.com/features/2005/05/gui/7/ adresinden 8 Mayıs 2017 tarihinde alınmıştır.

Internet: Mobile/Tablet Top Operating Systems (2016, June). Netmarketshare

Web: https://www.netmarketshare.com/downloads/guest6360/5877/ I3540000.pdf adresinden 9 Mayıs 2017 tarihinde alınmıştır.

Internet: Türk Dil Kurumu

Web: http://www.tdk.gov.tr adresinden 9 Mayıs 2017 tarihinde alınmıştır.

\section{Görsel Kaynakları}

Görsel I: http://www.oldcomputers.net/macintosh.html adresinden 3 Mayıs 2017 tarihinde alınmıştır.

Görsel 2: http://teced.com/wp-content/uploads/20I I/05/Low-fidelity-wireframe. jpg adresinden 9 Mayıs 2017 tarihinde alınmıştır.

Görsel 3: Ekran Görüntüsü, Adobe Experince Design CC, 10 Mayıs 2017 tarihinde alınmıştır. 